\title{
CICLO DA VIDA
}

Torrecele Hatunaka Javaé

Professor Alfabetizador

Entrevistei ancião Alcides Mahuaré Javaé no dia 10 de setembro de 2014, às 16 hrs. A entrevista sobre como confeccionar arco e flecha, depois de entrevistar, produzir um texto para levar na sala de aula e para explicar a importância para a cultura tradicional do povo Iny.

E também, quais materiais para utilizar para se fazer arco e flecha. Depois de feita, como pratica e explica também para ter cuidados para não ter acidente com arco e flecha.

Explicando também alguns exemplos de acidente de arco e flecha, alguns alunos perguntavam se seria possível a volta do uso da nossa arma tradicional como era antes, faz tempo não ver alguém utilizando arco e flecha na pescaria e na caça. Expliquei para ele que temos que valorizar a nossa cultura.

Júnior Hatxikure Javaé Professor Alfabetizador

Dia 03 outubro realizei entrevista às 9 hs com Lawatxiro Javaé, na aldeia São João - Ilha do Bananal - TO, como ela explicou nossos saberes, atividade dos homens como flecha. Quando o menino nasce, quando cresce o pai faz uma flecha de criança para treinar e para se acostumar, a idade pelo menos de 7 a 9 anos de idade, quando cresce para o rapaz ele mesmo faz flecha de verdade para pescar e caçar, aprendendo pelo pai, o avô, quando ele casa, tem filho para sustentar sua família com a flecha e também faz flecha de criança, quando ele fica vovô tem netos, também ensina os netos como faz flecha, como pescar e caçar com flecha. Quando ele ficar mais velho não dá conta de fazer flecha, nem pescar e caçar, ele fica sendo sustentado pelo filho, o neto, o genro, ele fica como ele era criança até chegar ao final da vida.

Assim ela explicou como é a nossa realidade de vida de atividade dos homens, explicou que é muito importante para fazer a 
nossa realidade para ficar na escrita, documentada, porque não está mais sendo realizada atividade dos homens, por isso importante para documentar nossos saberes do povo Javaé.

\section{Júnior Ohori Javaé} Professor Alfabetizador

No dia 20 de agosto de 2014 pesquisei o ancião Juraci Wasari Javaé sobre atividade masculina, explicou detalhadamente que as crianças indígenas Javaé, desde menino ensinado educado trabalho do homem com pessoa adulta ou tio, pai, avô da criança Javaé. Observa atividade que o pai fazendo com arco, flecha, remo, borduna e outros. Primeiramente, menino Javaé é ensinado quando está na fase de sete anos de idade a confeccionar flechinha. O pai, tio ou avô que faz e o menino olhando como fazer e depois ensina jogar flecha após ensinar a criança, vai a beira do rio caçar peixinho ou passarinhos para matar e praticando na vida, dia-a-dia, passando tempo quando com idade de dez já fazem flechinha a partir daí ele mesmo confecciona. Então vem crescendo, desenvolvem prática do homem, desde criança que menino Javaé é ensinado para saber regra masculino Javaé.

No dia 29 de agosto de 2014 encontro com orientadores Javaé, formadores e pesquisadores na aldeia Canuanã foi discutido tema do saberes indígenas como ciclo da vida da criança indígena Javaé, como menino e menina veem conhecimentos Javaé desde crianças, e também como ensinar na tradição do Javaé.

No dia 11 de setembro de 2014 pesquisa com anciã Luiza Lawatxiro Javaé sobre atividade feminina, menina indígena Javaé desde sete anos de idade é ensinada, aconselhada trabalho das mulheres, criança Javaé, através de observação ou de ensinar aprender a fazer atividade feminina. Primeiro, menina é ensinada a fazer preparação de fio de algodão, esteira, depois ensina, quando tem doze anos de idade, vem treinando a fazer esteira, prepara fio de algodão. Assim, mulher Javaé aprende a regra tradicional.

No dia 02 de outubro de 2014 atividade trabalhada referente à pesquisa atividade masculina na sala de aula com turmas de $2^{\circ}$ e $3^{\circ}$ anos de ensino fundamental através de desenhos e diálogo na 
oralidade na língua materna Javaé.

No dia 13 de outubro de 2014 foi trabalhada atividade feminina na sala de aula com as turmas de $6^{\circ}$ e $7^{\circ}$ anos de ensino fundamental, produzidos desenhos referentes ao trabalho do homem e da mulher, e explicação do desenho na língua nativa Javaé.
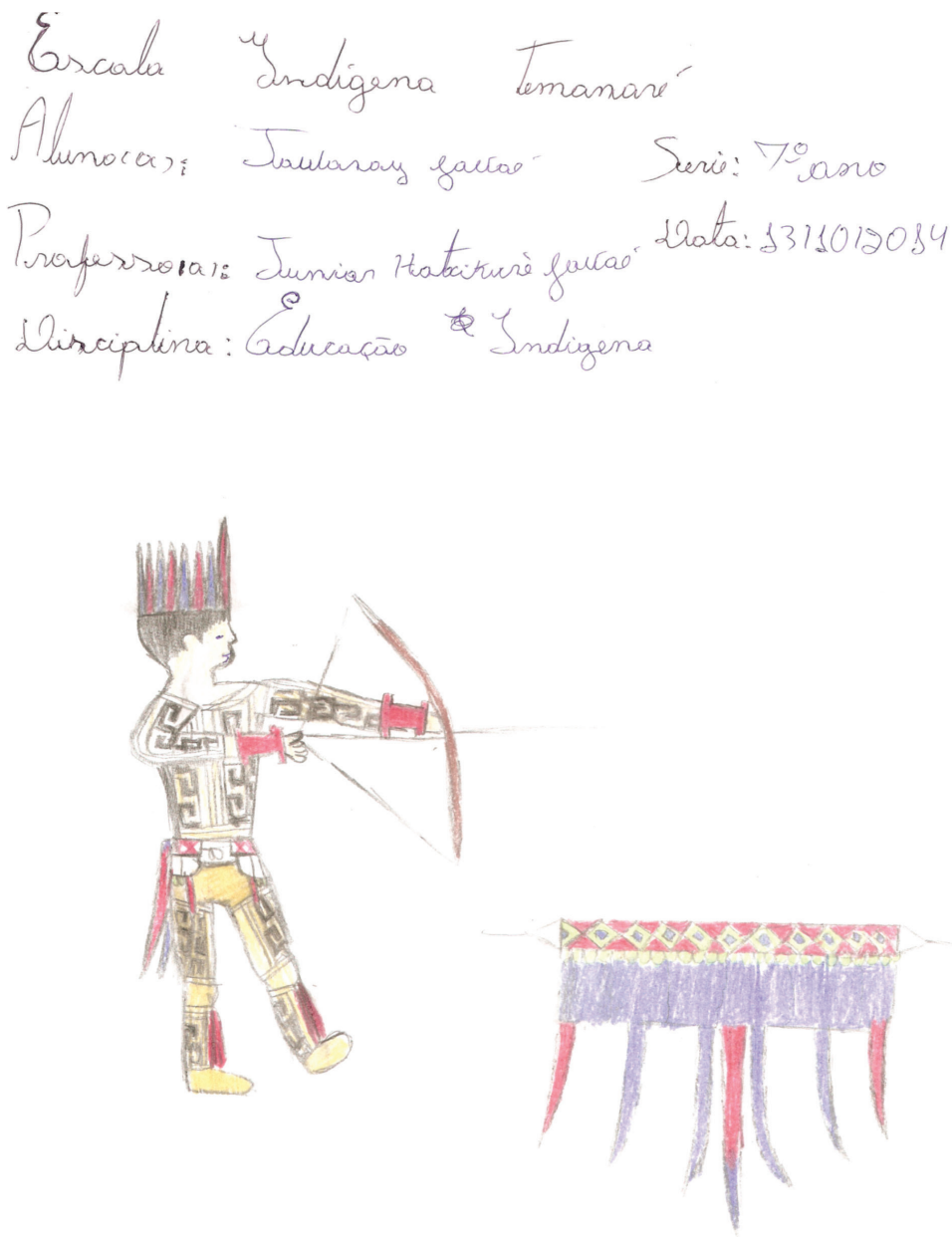


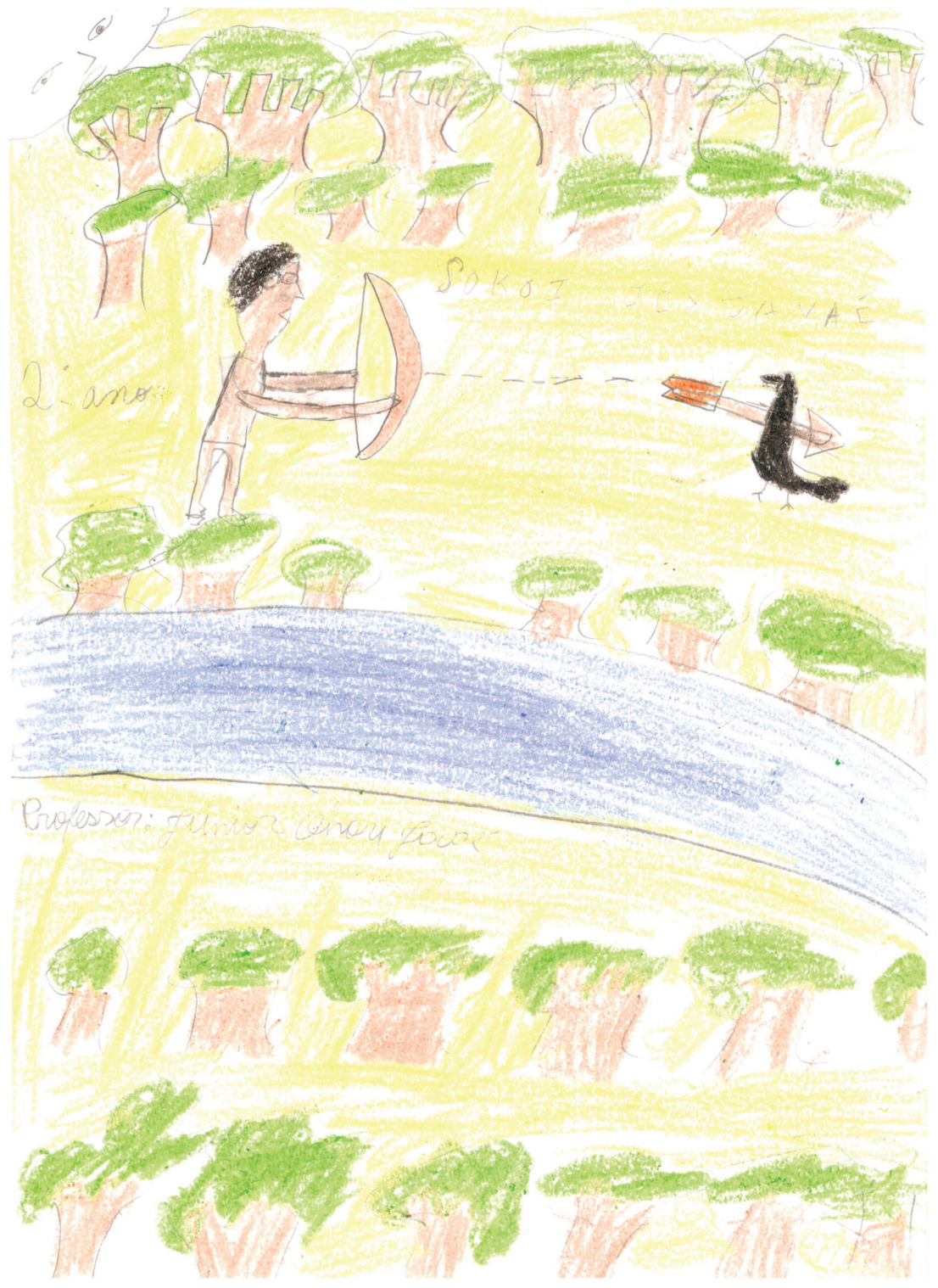

Dorivaldo Idiani Javaé Professor Alfabetizador

Hoje, uma educação escolar diferenciada e de qualidade intercultural e bilíngue ou multilíngue é reivindicação e parte dos 
projetos de vida de comunidade.

Todas as sociedades indígenas dispõem de seus próprios processos de fortalecimento de culturas e de formação das pessoas mobilizando indígenas para a educação.

Os momentos eatividades de ensino, aprendizagem combinam espaços e momentos formais e informais com concepções próprias sobre o que deve ser aprendido como quando por quem. A escola não deve ser vista como o único lugar de aprendizado. Também a comunidade possui sua sabedoria para ser comunicada, transmitida e distribuída por seus membros; são valores e mecanismos da educação tradicional dos povos indígenas. Essas formas de educação tradicional podem e devem contribuir na formação de uma política e educação adequadas.

Capazes de atender aos anseios, interesses e necessidades diárias da realidade atual. Tais conhecimentos não são incompatíveis com os conhecimentos da escola contemporânea.

Promover e fortalecer a língua e a cultura dos povos indígenas Javaé. Efetivar e zelar pela educação indígena. Educação do povo Javaé vem de casa, o pai e a mãe ensinam seus filhos dentro de sua casa. Por isso as crianças aprendem o mais rápido possível, sobre a utilização de material didático, como palha de coco babaçu, linha de algodão e pena de pássaro.

Assim funciona a educação indígena do povo Javaé. 
Ricardo Tewaxi Javaé

Professor Alfabetizador

No dia 13 de agosto de 2014, pesquisei o Sr. Burahi Javaé, ancião da aldeia que eu sempre pesquiso, para saber sobre respeito e educação na cultura Javaé. Ele me disse que a educação sempre vem da família, a criança desde pequena faz a sua cumprimentação na própria família com os tios maternos e paternos, então assim é a educação do povo Javaé, porque a cumprimentação é uma educação e respeito na nossa cultura Javaé, porque hoje em dia os mais novos estão deixando de praticar a cumprimentação na comunidade, então a criança vai aprendendo conforme a convivência da família, a pesquisa para fortalecer a cumprimentação na cultura Javaé, porque só mais velho faz a sua cumprimentação.

No dia 29 de agosto reunimos com os professores de cada escola na escola indígena Taina, na aldeia Canoanã, o objetivo da reunião foi sobre os saberes indígenas, como foram as pesquisas dos orientadores, como Samuel Iòlò Javaé, Tewaxi Javaé, Kurisi Javaé, então começou a discussão. O professor Samuel Iòlò começou a palestra sobre a pesquisa sobre o ciclo de vida do povo Javaé. Samuel Saburua Javaé levanta a questão de não saber como trabalhar os saberes indígenas na sala de aula com os alunos, o professor Werehatxiari fez a mesma pergunta e eles foram esclarecidos na discussão, o participante Josivaldo Tejuare ajudou com o conhecimento dele, citou um exemplo do menino que não podia comer a cabeça do peixe, só comia a parte do meio porque os mais novos não praticam mais o conhecimento dos mais velhos. Assim foi trabalhado o conhecimento do povo Javaé. 


\section{Ruruca Javaé Professor Alfabetizador}

A realização da pesquisa na Aldeia São João aconteceu no domingo às $14 \mathrm{~h} 30 \mathrm{~min}$ da tarde, iniciei a entrevista com uma anciã chamada Luiza Lawatxiro Javaé, no dia 27 de agosto de 2014, a pesquisa sobre a preparação do homem para o trabalho.

Depois de realizar a pesquisa, ministrei uma aula para os alunos sobre a preparação do homem para o trabalho, apliquei a atividade das $18 \mathrm{~h} 30$ às $19 \mathrm{~h} 18$ para o ensino médio da $1^{\mathrm{a}} \mathrm{e} 2^{\mathrm{a}}$ séries para realizar o desenho de acordo com o tema contextual, até que os alunos fizeram as perguntas como é que eles vão realizar a atividade e explique bem detalhadamente para eles entenderem melhor, e depois fizeram o desenho bem caprichado e também gostaram muito dessa atividade.

Antigamente a preparação do homem para o trabalho começava desde criança, quando chegava na fase do rapaz, faz mais do que antes da preparação e quando acontece o casamento tradicional faz mais a preparação para sustentar a sua família de acordo com o seu trabalho cotidiano, para isso que existe a preparação do homem para o trabalho.

A preparação é muito importante para as novas gerações, só que eles consideram como o mito, mas os nossos antepassados diziam como a verdade para os jovens se preparem como eles se preparavam nos tempos passados. 


\section{PRONOME DE TRATAMENTO JAVAÉ (INY)}

Pesquisa foi com minha tia Doralice Nowa Javaé em maio/ junho de 2014 sobre pronome de tratamento Javaé (Iny) é a forma de receber ou cumprimentar a pessoa mais velha, que faz parte da educação das crianças Iny Javaé, porque hoje a nova geração não conhece a forma de tratar a pessoa mais velha (o), exemplo:

$$
\begin{aligned}
& \text { Diarỹ }=\text { eu } \\
& \text { Kai }=\text { tu/você } \\
& \text { Tiki }=\text { ele/ela }
\end{aligned}
$$

1. A fala masculina tii e feminina tiki

$$
\text { Tiki boho }=\text { eles/elas }
$$

2. A fala masculina tii e feminina tiki, a palavra boho é quando a palavra está no plural

$$
\text { Iny boho }=\text { nós }
$$

A palavra mais importante de ensinar e praticar essas palavras de tratamento para respeitar a pessoa mais velha (o), masculino e feminino.

3. Forma de tratar o respeito do masculino:

Wa $\left\{\begin{array}{l}\text { Ixi (chamar a pessoa mais nova) } \\ \text { Nyrỹ (chamar a pessoa mais velha) } \\ \text { Haura (tio parte do pai mais velho ou mais novo) } \\ \text { Labyry (tio parte da mãe mais velha ou mais novo) } \\ \text { Labie (avô pessoa mais velha) }\end{array}\right.$ 
4. Forma de tratar o respeito do feminismo:

Wa $\left\{\begin{array}{l}\text { Nymy } \\ \text { Esoru } \\ \text { Lahi } \\ \text { Lajirà }\end{array}\right.$

Lerỹ e Majiura não se usam antes de "wa", porque a palavra "wa" significa minha ou meu, só tem que entender a forma de usar no masculino e no feminino.

Essas formas de tratamento o respeito é para falar ou cumprimentar a mulher, como na língua portuguesa, bom dia, boa tarde, boa noite. Isso tudo que foi pesquisado com minha tia Doralice Nawa Javaé, essas palavras são a forma de tratar as pessoas mais velhas

No mês de agosto de 2014 a pesquisa foi aplicada na sala de aula, comentário junto com os alunos, quais são utilizados para masculino e feminino, porque hoje em dia a nova geração não sabe, não conhece quais são as palavras que são utilizadas para a pessoa mais velha. A palavra "awire" não é a cumprimentação correta dos Iny, não significa bom dia, boa noite, boa tarde, mesmo assim a palavra "awire" vem subordinando no lugar da cumprimentação correta palavra certa para significar "awire" são: bom, boa, maravilha, legal, bonita, elegante, pode indicar para pessoa ou objeto. 